\title{
Repeatability and Learning Effect in the 6MWT in Preoperative Cancer Patients Undergoing a Prehabilitation Program
}

Raquel Sebio-García ( $\square$ raquelsebio@gmail.com )

Hospital Clinic de Barcelona https://orcid.org/0000-0002-7167-4737

\section{Fernando Dana}

Hospital Clinic de Barcelona

Elena Gimeno-Santos

Hospital Clinic de Barcelona

Manuel López-Baamonde

Hospital Clinic de Barcelona

Marta Ubré

Hospital Clinic de Barcelona

Mar Montané-Muntané

Hospital Clinic de Barcelona

Raquel Risco

Hospital Clinic de Barcelona

Monique Messagi-Sartor

Hospital Clinic de Barcelona

Josep Roca

Hospital Clinic de Barcelona

Graciela Martínez-Pallí

Hospital Clinic de Barcelona

\section{Research Article}

Keywords: Six-Minute Walk Test, Repeatability, Prehabilitation, Cancer

Posted Date: December 8th, 2021

DOI: https://doi.org/10.21203/rs.3.rs-1039238/v1

License: (c) (1) This work is licensed under a Creative Commons Attribution 4.0 International License.

Read Full License 
Version of Record: A version of this preprint was published at Supportive Care in Cancer on February 28th, 2022. See the published version at https://doi.org/10.1007/s00520-022-06934-6. 


\section{Abstract \\ Objective}

the main objective was to assess repeatability and learning effect of the six-minute walk test (6MWT) in a cohort of preoperative cancer patients referred to a prehabilitation program. As a secondary objective we aimed to identify determinants of improvement in the second test.

\section{Materials and Methods}

secondary analysis from a large prospective study on the implementation of a multimodal prehabilitation program in a real-life scenario. Eligible patients were assessed at baseline before starting the prehabilitation program. The 6MWT was conducted according to the American Thoracic Society (ATS)/ European Respiratory Society (ERS) guidelines with two tests being performed under identical conditions separated by 30 minutes. The distance covered (in meters) and the physiological responses (heart rate, oxygen saturation, fatigue and dyspnea) to each test were recorded and compared.

\section{Results}

170 patients (60.9\%) were analyzed. Repeatability of the distance covered with the 6MWT was excellent $(I C C=0.98 ; 95 \% \mathrm{Cl}: 0.92-0.99)$, but a mean increase of +19.5 meters $(95 \% \mathrm{Cl}: 15.6-23.5 \mathrm{~m} ; \mathrm{p}=<.001)$ in the second test was found, showing a learning effect with limits of agreement between -31.3 and $70.4 \mathrm{~m}$. Coefficient of variation was $4 \%$. No clinical factor was found to be associated with an improvement in the second test.

\section{Conclusions}

the 6MWT showed excellent repeatability in preoperative cancer patients, but a significant learning effect is present. No associated factors with a clinically meaningful improvement in the second test were identified. In light of these findings, two attempts of the 6MWT should be encouraged in this population.

\section{Introduction}

The six-minute walk test (6MWT) is a very common measurement of physical performance in different clinical populations [1, 2] especially in cardiorespiratory settings [3-5]. Although several alternatives of the test have been proposed including 12-, 6-, 3- and 2-minute variations, the 6-minute version stands as the most used both in clinical practice and research studies since it has shown the best test-retest reliability and reproducibility [6]. Over the past decades, as a result of a noticeable growth in the field of oncology rehabilitation and exercise, the use of the 6MWT has increased in this population although studies on its test-retest reliability are scarce [7]. In patients with cardiorespiratory diseases where the 
6MWT has been most widely applied, the test-retest reliability was found to be excellent with intra-class correlation coefficients (ICC) ranging from 0.88 to 0.99 [8-12]. However, despite this high correlation, most studies have reported improvements in the distance covered during the second test, indicating the existence of a learning effect which has led to a recommendation of performing a re-test $[9,13]$. In cancer patients, the level of agreement in test-retest of the 6MWT has also been assessed in a sample of 30 patients across the disease continuum showing an ICC of 0.93 ( $95 \% \mathrm{Cl}: 0.86-0.97)$ and a coefficient of variation of $3 \%$ [14]. In line with what has been observed in other clinical populations [15], the 6MWT also showed a learning effect, with $80 \%$ of patients walking further in the second test.

The 6MWT is widely used to assess functional capacity before and after a prehabilitation program in the setting of cancer surgery [16] as well as to stratify patients according to surgical risk [17] given that functional capacity has been linked to postoperative outcomes in several surgical populations [18-21]. Because accurate measurement of functional capacity is important for both purposes, quantification of the learning effect of the 6MWT in this population is key to determine the need for a practice test. However, to date no study has assessed the repeatability (also termed test-retest reliability in the literature) of the 6MWT in a large sample of cancer patients scheduled for tumor resection surgery. Because in the scientific literature the terms of test-retest reliability, reproducibility and repeatability are frequently used indistinctly to analyze measurement errors of a test over time, it's important to discern these terms and define their scope of application. As repeatability specifically refers to the level of agreement between two measurements undertaken in a short period of time over identical conditions [22] we will focus on this term for the purpose of this study.

Therefore, the primary aim of this study was twofold: 1) to assess the within-subject repeatability of the $6 \mathrm{MWT}$ in a cohort of early-diagnosed cancer patients awaiting major surgery and 2) to quantify the learning effect of the test in this population. As a secondary objective, we aimed to identify potential determinants of distance improvement in the second test.

\section{Materials And Methods}

\section{Design}

This study is a sub-analysis stemming from a previous large prospective longitudinal study on the implementation of a multimodal prehabilitation program in a real-world scenario (NCT02976064). Patients were informed on the purpose of the study by an anesthesiologist and signed informed consent prior to any testing. The study was approved by the local Ethics Committee (HCB/2016/0883).

\section{Participants}

Eligible participants were consecutive patients scheduled for tumor resection surgery at Hospital Clinic de Barcelona between 2018 and 2020 who were invited to participate in a multimodal prehabilitation program. Specific inclusion criteria were: 
- Patients undergoing major oncological surgery (digestive tract, gynecological, pancreatic, thoracic, urological).

- High risk for post-operative complications (i.e., American Society of Anesthesiologists (ASA) physical status classification III - IV and/or age $\geq 70$ years old and/or Duke Activity Status Index (DASI) $<46$ points)[23].

- Severe deconditioning in patients undergoing highly aggressive surgeries (i.e: Clinical Frailty Scale (CFS) $\geq 4$ and/or diagnosis of malnutrition according to the Global Leadership in Malnutrition GLIM criteria).

Exclusion criteria included patients with severe musculoskeletal, neurological, or cognitive impairments who were unable to complete the tests and questionnaires in the prehabilitation program and those scheduled for surgery within 3 weeks.

\section{Procedures}

Patients who met the inclusion criteria were appointed for a baseline assessment in our Prehabilitation Unit. Patients were assessed by four different healthcare professionals: an anesthesiologist, who assessed surgical risk (ASA score), comorbidities (Charlson Comorbidity Index), performance status (DASI) and frailty (CFS); a nutritionist, who performed an assessment of the nutritional profile including analysis of prealbumin and albumin levels and malnutrition according to GLIM criteria; a psychologist, who explored expectations regarding surgery including anxiety and depression status using the Hospital Anxiety and Depression Scale (HADS) as well as readiness to change, and a physiotherapist, who performed a battery of physical tests including handgrip strength, 6MWT, and the 30-second Sit-to-Stand test (STS) in addition to an assessment of physical activity levels using the Yale Physical Activity Survey (YPAS) [18].

The 6MWT was performed in accordance with the American Thoracic Society (ATS)/European Respiratory Society guidelines [4] by the same trained physiotherapist who walked behind the patient on two attempts separated by at least 30 minutes. Patients were encouraged to walk as fast as they could during 6 minutes on an inside 30-metres long flat corridor. Standardized encouragement was given each minute as recommended and the physiotherapist walked behind the patient at all times. Oxygen saturation $\left(\mathrm{SpO}_{2}\right)$, heart rate, dyspnea and leg fatigue according to the modified Borg Scale [24] were recorded at the beginning and at the end of each test, as well as during the first two minutes of recovery. Oxygen saturation and heart rate were also continuously monitored and recorded at each lap using a portable pulse oximeter (Nonin ${ }^{\circledR} 3150$ Wrist Oximeter). Oxygen desaturation was defined as a decrease in $\mathrm{SpO}_{2} \geq 4 \%$ from baseline.

Once the patient was evaluated, a 4-week personalized prehabilitation program including exercise training, nutritional and psychological support and medical optimization was initiated. Before surgery, patients were re-assessed in terms of nutritional, psychological and exercise training adherence with the $6 \mathrm{MWT}$ being used to monitor the functional capacity improvement. 


\section{STATISTICAL ANALYSES}

A descriptive analysis of baseline relevant data was initially performed, including the responses of both first and second 6MWT. Normal distribution of the data was assessed using the Kolmogorov-Smirnov test. The intra-class correlation coefficient (ICC) and the coefficient of variation (CV) were used to assess replicability of both $6 \mathrm{MWT}$, with $95 \% \mathrm{Cl}$ added to assess for systematic error between test and re-test. A Bland-Altman plot was used to evaluate agreement between the first and second test. Proportional bias was analyzed through a linear regression model. Coefficient of variation (CV) was calculated as the ratio between the standard deviation (SD) and the mean. Paired t-tests were conducted to compare physiological variables of both 6MWT after checking for normality. Ordinal data was assessed with nonparametric tests (Chi Square). Finally, independent t-tests were used to compare patients' characteristics between those improving in the second test and those who did not. Bivariate comparisons were also performed to identify potential correlations between the variables studied and increasing $\geq 14$ meters in the second $6 \mathrm{MWT}$, according to the lower limit for a minimal clinically important difference (MCID) found in several clinical populations [25]. Analyses were performed using SPSS version 21 (IBM Corporation, Chicago IL). A $p$ value $<.05$ was considered for statistical significance in all analyses.

\section{Results}

Baseline characteristics of the patients are summarized in Table 1. Between May 2018 and March 2020, 279 oncological patients were consecutively screened for prehabilitation. We were able to obtain full data on both $6 \mathrm{MWT}$ in 170 patients $(60.9 \%)$. Seventeen patients (6\%) were excluded due to logistic limitations to attend the prehabilitation program and were not evaluated; 72 patients $(25.8 \%)$ did not complete a second 6MWT due to several reasons (patient refused because of excessive fatigue or insufficient time among others) and on 20 patients (7.2\%) there was some missing data from the second test. No differences were found between included and excluded participants for any relevant data $(p>05)$ 
Table 1

Baseline characteristics of the patients included $(n=170)$

\begin{tabular}{|ll|}
\hline Variable & \\
\hline Gender (n, \%) & $114(67.1)$ \\
\hline Age, years (mean, SD) & $71.1(14.9)$ \\
\hline BMI, kg/m² (mean, SD) & $26.5(4.8)$ \\
\hline ASA Score (n, \%) & $69(40.6)$ \\
I & $84(49.4)$ \\
III & $13(7.6)$ \\
IV & $4(2.4)$ \\
\hline Type of surgery (n, \%) & \\
Colorectal & $65(38.2)$ \\
Upper GI & $36(21.2)$ \\
Pancreatic & $8(4,7)$ \\
Urologic & $44(25.9)$ \\
Gynecologic & $7(4.1)$ \\
Cytorreductive/HIPEC & $3(1.8)$ \\
Other & $7(4.1)$ \\
Neoadyuvancy (n, \%) & \\
No & $112(65.9)$ \\
Chemotherapy & $37(21.8)$ \\
Chemoradiotherapy & $4(2.4)$ \\
& $17(10)$ \\
\hline
\end{tabular}




\begin{tabular}{|ll|}
\hline Variable & \\
\hline CS $(n, \%)$ & $4(2.9)$ \\
0 & $21(15.4)$ \\
1 & $61(44.9)$ \\
2 & $26(19.1)$ \\
3 & $10(7.4)$ \\
4 & $14(10.3)$ \\
\hline 5 & \\
\hline Charlson Comorbidity Index (mean, SD) & $5.55(2.5)$ \\
\hline
\end{tabular}

Abbreviations: ASA: American Society of Anesthesiologists; BMI: Body Mass Index; CSF: Clinical Functional Scale; HIPEC, Hyperthermic Intraperitoneal Chemotherapy

Measurements were performed by the same operator and a total of four highly-trained physiotherapists participated in data collection of the tests. The ICC for the distance walked during the 6MWT showed excellent repeatability between both tests (ICC $=0.98 ; 95 \% \mathrm{Cl}: 0.92-0.99)$ and the coefficient of variation (CV) was $4 \%$. Patients walked a mean distance of $456 \pm 111 \mathrm{~m}$ during the first test and $475 \pm 112 \mathrm{~m}$ during the second test, corresponding to a mean increase in the distance walked during the second test of 19.5m (95\% Cl: $15.6-23.5 \mathrm{~m} ; \mathrm{p}=<.001$ ) with limits of agreement between -32.3 and 70.38 meters (Figure 1). The improvement was similar between men and women as well as older and younger subjects (Table 2). 
Table 2

Physiological responses to both 6MWT

\begin{tabular}{|c|c|c|c|c|}
\hline Variable & 1st 6MWT & 2nd 6MWT & Mean Difference $(95 \% \mathrm{Cl})$ & $P$ value \\
\hline Distance (meters)* & $455.69(8.5)$ & $475.24(8.6)$ & +19.5 (15.6 - 23.5) & $<.0001$ \\
\hline Men & $479.3(96.7)$ & $498.9(99.1)$ & +19.6(14.4 - 24.7) & \\
\hline Women & $407.3(123.6)$ & $427.1(121.5)$ & +19.5 (13.7 - 25.3) & \\
\hline$<70$ years $(n=79)$ & $517.6(86.3)$ & $536.8(85.2)$ & +19.2(13.4 - 25) & \\
\hline$>70$ years & $402(102.5)$ & $421.8(104.9)$ & +19.8 (14.4 - 25.2) & \\
\hline Baseline HR (bpm) & $82.4(1.3)$ & $82.75(1.1)$ & $-0.3(-1.9,+1.3)$ & NS \\
\hline Final HR & $111.8(1.9)$ & $114.84(1.4)$ & $-3(-4.4,-1.6)$ & $<.0001$ \\
\hline$\triangle H R^{\star \star}$ & $29.4(15.7)$ & $32.1(14.3)$ & $-2.68(-0.5,-4.8)$ & .013 \\
\hline Baseline SpO2 & $95.8(0.3)$ & $95.6(0.1)$ & $0.2(-0.05,+4.5)$ & NS \\
\hline Final SpO2 & $94.6(0.3)$ & $94.6(3.1)$ & $0.04(-0.2,+0.3)$ & NS \\
\hline$\triangle \mathrm{SpO} 2^{\star \star}$ & $1.22(3)$ & $1.1(2.5)$ & $0.15(-0.15,0.48)$ & NS \\
\hline Baseline Dyspnea & $0(0-0)$ & $0(0-0)$ & - & NS \\
\hline Final Dyspnea & $2(1-3)$ & $2(1-3)$ & - & NS \\
\hline$\triangle$ Dyspnea** $^{\star *}$ & 2 & 2 & - & NS \\
\hline Baseline Fatigue & $0(0-1)$ & $0(0-1)$ & - & NS \\
\hline Final Fatigue & $2(0-3)$ & $2(0-3)$ & - & NS \\
\hline$\triangle$ Fatigue $^{\star \star}$ & 2 & 2 & - & NS \\
\hline HRR1 & $93.66(16.9)$ & $95.19(18.6)$ & $1.5(8)$ & .016 \\
\hline$\triangle$ Final HR - HRR1 & $18.1(11.2)$ & $20(12.4)$ & $-1.7(-3.4,-.1)$ & .038 \\
\hline \multicolumn{5}{|c|}{$\begin{array}{l}\text { Abbreviations: } 6 \mathrm{MWT} \text { : } 6 \text {-minute walking test; } \mathrm{HR} \text { : heart rate; } \mathrm{Bpm} \text { : beats per minute; } \mathrm{SpO}_{2} \text { : oxygen } \\
\text { saturation; HRR1: heart rate recovery } 1 \text { st minute }\end{array}$} \\
\hline \multicolumn{5}{|c|}{$\begin{array}{l}\text { *Data are presented as mean (standard deviation) with the exception of dyspnea and fatigue which } \\
\text { are expressed as median (interquartile range) }\end{array}$} \\
\hline \multicolumn{5}{|c|}{${ }^{* \star}$ Change between final and baseline values } \\
\hline
\end{tabular}

Physiological responses to both 6MWT are found in Table 2. We observed an increase in the maximum heart rate achieved during the second test, both in absolute values and in percentage of maximum predicted $(70.6 \%$ vs. $72.5 \%$ respectively; $p=.006)$. The ICC for the mean change in HR between both tests 
(maximum - baseline) was 0.71 (95\% Cl: $0.6-0.78 ; p<.0001)$. No differences were found in final dyspnea and leg fatigue ( $p>.05$ ) between the first and the second attempt, with ICC ranging from 0.6 for dyspnea to 0.71 for leg fatigue. Oxygen saturation responses showed a desaturation (decrease from baseline $\geq 4 \%)$ in 12 patients $(7.1 \%)$ during the first test and $9(5.3 \%)$ during the second $(p<.0001)$.

The vast majority of the patients (80\%) walked farther on the second test and $58 \%$ of those increased the distance walked in 14 meters or more. When comparing patients who showed an improvement of $\geq 14$ in the second 6MWT vs. those with no improvement, no differences were found for any of the assessed variables ( $p>$.05) (Table 3). In addition, no significant correlation was found in the univariate analysis between any of the clinical characteristics and improving $\geq 14$ meters in the second test.

Table 3

Comparison between patients improving $\geq 14$ meters in the 2 nd $6 \mathrm{MWT}$ and those with a change $<14$ meters

\begin{tabular}{|c|c|c|c|}
\hline Variable & $\begin{array}{l}\Delta \geq 14 \text { meters } \\
(n=100)\end{array}$ & $\begin{array}{l}\Delta<14 \text { meters } \\
(n=70)\end{array}$ & $P$ value \\
\hline 1st 6MWT, meters (mean, SD) & $464.6(117.1)$ & $451.3(108.5)$ & NS \\
\hline Age, years (mean, SD) & $70.2(9.5)$ & $72.3(9.9)$ & NS \\
\hline Gender (n, \%) & $67(67)$ & $47(67)$ & NS \\
\hline \multicolumn{4}{|l|}{ Male } \\
\hline ASA $(n, \%)$ & $92(92)$ & $61(87.5)$ & NS \\
\hline $\mathrm{H}$ & $8(8)$ & $9(12.5)$ & \\
\hline \multicolumn{4}{|l|}{ III-IV } \\
\hline Neoadjuvancy $(\mathrm{n}, \%)$ & $14(25)$ & $44(38.6)$ & NS \\
\hline Yes & $42(75)$ & $70(61.4)$ & \\
\hline \multicolumn{4}{|l|}{ No } \\
\hline Charlson comorbidity index $(n, \%)$ & $5.5(2.4)$ & $5.6(2.6)$ & NS \\
\hline $\mathrm{BMI}, \mathrm{kg} / \mathrm{m}^{2}$ (mean, SD) & $27.1(21.1)$ & $25.7(4.8)$ & NS \\
\hline STS, repetitions (mean, SD) $(n=167)$ & $13.2(5.3)$ & $14.5(5.9)$ & NS \\
\hline YPAS (mean, SD) $(n=136)$ & $38.3(22.2)$ & $34.9(20)$ & NS \\
\hline $\begin{array}{l}\text { Handgrip Strength, kg (mean, SD) } \\
(n=153)\end{array}$ & $28.4(10)$ & $29.1(9.4)$ & NS \\
\hline $\operatorname{HADS}($ mean, SD) $(n=135)$ & $8.6(6.3)$ & $7.8(5.8)$ & NS \\
\hline
\end{tabular}




\section{Discussion}

Results from this study found that the 6MWT appears to be highly repeatable in oncological patients scheduled for major surgery. Nonetheless, the high proportion of patients increasing the distance covered during the second 6MWT shows that a learning effect in this population, as observed previously in other clinical settings [15]. Unfortunately, no determinator of improvement was found among the variables studied. These findings suggest that performing at least two attempts is recommended in preoperative cancer patients to accurately determine patients' functional capacity.

Over the last years, increasing evidence has been generated on the potential of prehabilitation to optimize physical and psychological resilience to cope with stress generated by major oncological surgical procedures [26] and 6MWT distance is usually considered an outcome of prehabilitation programs [27]. Guidelines to perform the 6MWT were first published by the American Thoracic Society (ATS) over 20 years ago [28] and initially stated that a practice test was not necessary for most clinical scenarios as the mean change from the first to the second was considered to be low. However, several authors have since then recommended using a familiarization trial to establish a baseline 6MWT $[9,29,30]$ while some other studies have neglected the need for a second test [31, 32]. In patients which chronic respiratory diseases as well as cardiac failure, studies have shown that there is a significant difference in the distance covered between the first and the second test, with improvements ranging from 24 to 29 meters [15]. Indeed, a systematic review and meta-analysis conducted in 2014 in COPD, found a pooled mean increase of $26.1 \mathrm{~m}$ in the second test [8]. Furthermore, this learning effect seems to exist not only when the tests are performed on the same day but also when performed separated by several weeks or months [30,33]. In cancer patients, the study conducted by Schmidt et al. [14], also showed a mean increase in the second test of $16.6 \pm 29.9 \mathrm{~m}$ ( $95 \% \mathrm{Cl}$ : $5.5-27.8)$ with $80 \%$ of the patients walking farther than on the first attempt, which is consistent with our results. Our findings conducted in a more heterogenous sample of recently diagnosed cancer patients, confirmed that there is indeed a learning effect in this population (mean difference $19.5,95 \% \mathrm{Cl}: 15.6$ - 23.5) with $80 \%$ of patients walking more during the second test. The Bland-Altman plot further confirmed this difference with limits of agreement ranging from -31.3 to $70.4 \mathrm{~m}$, well over the MCID reported for several clinical populations [25]. As performing a second 6MWT is timeconsuming (an additional 40 minutes including resting from the first test and performing the second) and sometimes it is not well accepted by the patient (severe deconditioning, musculoskeletal impairments, etc.), it would be of great interest to identify potential factors associated with presumably improving the distance walked during the second test. This would allow us to select those patients in which a second test might be necessary for reliable results. Unfortunately, we were not able to identify any determinator of significant improvement among the clinical and anthropometric variables assessed in this study. In addition, no differences in the magnitude of learning effect were found between men and women neither between older and younger patients, which suggest that the variability is due to within subject factors (motivation, readiness, fatigue, etc.). As so, two attempts of the test should be encouraged in this population to accurately assess functional capacity. Nevertheless, in some scenarios, the clinical decision of performing a practice test or not could depend on the purpose of the assessment [34] and well as the baseline level of functional capacity (i.e: patients walking $\geq 500$ meters might not need a second test if 
the purpose is assessing the surgical risk as they would be already considered low-risk). Undoubtedly, more studies are warrant in this line to determine whether one test could be enough in these cases.

Despite the existence of a learning effect reported in many clinical populations, the 6MWT has shown an excellent test-retest reliability and reproducibility across different populations including chronic cardiovascular and respiratory diseases [15, 31, 35], neurological conditions[36, 37] as well as healthy subjects [31]. However, when comparing studies, we observe that terminology used in these studies (reproducibility, replicability and reliability) is sometimes used interchangeably when they actually refer to different test properties, which hinders the interpretation and comparison of the results across studies. While reproducibility requires measurements to be undertaken under different conditions (i.e: different assessors or different populations), repeatability is measured under identical circumstances over a short period of time [22]. Both constructs are usually assessed with the ICC to quantify reliability between the measurements and/or determination of agreement with a Bland-Altman plot [38]. In our study, as in previous studies with smaller samples in cancer patients [7, 39], we found an ICC of 0.98 between two 6MWT conducted under identical conditions, showing excellent repeatability. In addition, the coefficient of variation was very low and similar to other previous studies $[5,14]$. Furthermore, no proportional bias was found showing that limits of agreement do not change significantly with different mean values of the test. So, although this is not the first study to evaluate the reliability and repeatability of the test in a cancer population, it is definitely the one with the highest and heterogeneous sample. In addition, the quality of our data was reinforced by the replicability of the physiological responses observed in both tests (ICC ranging from 0.6 to 0.83 ).

This study has some limitations that we must address. To start with, this is a sub-analysis derived from a large longitudinal study whose main objective was to analyze the feasibility and effectiveness of a multimodal prehabilitation program in a real-world scenario. Therefore, the sample size used might not be adequate for some of the analysis performed (i.e: identify potential factors associated with a meaningful change in the second 6MWT), although similar studies have been conducted where sample sizes are considerable smaller than ours $[14,39]$. In addition, a selection bias might have occurred as some of the patients were excluded from the final sample due to missing data on the 6MWT or refusal to perform a second test. However, in this case, after conducting an exploratory analysis between excluded and included patients, no relevant differences in clinical characteristics were found besides the excluded patients being more likely men $(p<.05)$.

In summary, this study provides new evidence that the 6MWT is a highly replicable test with consistent agreement to assess functional capacity in preoperative cancer patients who are scheduled for major surgery, but with a significant learning effect. Therefore, our findings support the recommendation of a practice 6MWT at baseline assessment for most clinical scenarios. Future studies are needed to determine whether one test could be enough in some selected cases (for instance, highly functional patients).

\section{Declarations}




\section{ACKNOWLEDGMENTS}

We would like to acknowledge the staff members of the Prehabilitation Unit at Hospital Clínic de Barcelona and for their collaboration to the achievement of this work.

The Hospital Clínic de Barcelona Prehabilitation Group: Maria José Arguis (MJA), Anael Barberán-García (AB), Betina Campero (BC), Isaac Cano (IC), David Capitán (DC), Ana Costas (AC), Fernando Dana (FD), Elena Gimeno-Santos (EG), Rubén González (RG), Antonio M Lacy (AML), Sara Laxe (SL), Antonio López (AL), Manuel López-Baamonde (MLB), Graciela Martínez-Pallí (GMP), Monique Messaggi-Sartor (MMS), Mar Montané-Muntané (MM), Ricard Navarro-Ripoll (RN), Amaia Peláez (AP), Juan M Perdomo (JP), Raquel Risco (RR), Josep Roca (JR), Barbara Romano-Andrioni (BR), Raquel Sebio-Garcia (RS), Marina Sisó (MS), Beatriz Tena (BT), Silvia Terés (ST), Marta Ubré (MU) and Francisco J Vega (FV).

\section{Funding}

The authors would like to acknowledge the support from the partners from the PAPRIKA project (https://eithealth.eu/project/paprika/), FIS-Smart PITeS (PI18/00841) and FIS (PI13/ 04255, PI17/00852, PI20/00835).

\section{Conflict of interest/Competing interests}

No conflict of interest to declare

\section{Availability of data and material}

Data could be available upon request if considered by the corresponding author

\section{Code availability}

Not applicable

\section{Author's contribution}

RSG, FD and GMP conceived the present idea. RSG, EGS and MSM carried out the measurements and collected data. GMP, MLB, RR, MMM and MU were responsible for patients' assessment and referral to the prehabilitation Unit and they contributed to data collection. JR and RSG conducted the statistical analysis. The manuscript was written by RS and GMP with significant contributions from all the authors who approved the final version.

\section{Ethics approval}

The study was approved by the local ethics committee (HCB/2016/0883).

\section{Consent to participate}


All patients gave written and oral consent to participate in the study before any formal testing.

\section{Consent for publication}

Not applicable

\section{References}

1. Enright PL (2003) The six-minute walk test. Respir Care 48(8):783-5

2. Santana MG, de Lira CAB, Passos GS, Santos CAF, Silva AHO, Yoshida CH et al (2012) Is the sixminute walk test appropriate for detecting changes in cardiorespiratory fitness in healthy elderly men? Journal of Science and Medicine in Sport [Internet]. ;15(3):259-65. Available from: http://dx.doi.org/10.1016/j.jsams.2011.11.249

3. Du H, Wonggom P, Tongpeth J, Clark RA (2017) Six-Minute Walk Test for Assessing Physical Functional Capacity in Chronic Heart Failure, vol 14. Current Heart Failure Reports. Current Science Inc., pp 158-166

4. Holland AE, Spruit MA, Troosters T, Puhan MA, Pepin V, Saey D et al (2014) An official European respiratory society/American thoracic society technical standard: Field walking tests in chronic respiratory disease. Eur Respir J 44(6):1428-1446

5. Kervio G, Ville NS, Leclercq C, Daubert JC, Carré F (2004 Sep) Intensity and daily reliability of the sixminute walk test in moderate chronic heart failure patients. Arch Phys Med Rehabil 85(9):1513-8

6. Butland RJA, Pang J, Gross ER, Woodcock AA, Geddes DM (1982) Two-, six-, and 12-minute walking tests in respiratory disease. British medical journal (Clinical research ed) 284(6329):1607-8

7. Eden MM, Tompkins J, Verheijde JL Reliability and a correlational analysis of the 6MWT, ten-meter walk test, thirty second sit to stand, and the linear analog scale of function in patients with head and neck cancer.Physiotherapy Theory and Practice 2018 Mar4;34(3):202-11

8. Singh SJ, Puhan MA, Andrianopoulos V, Hernandes NA, Mitchell KE, Hill CJ et al (2014) An official systematic review of the European Respiratory Society/American Thoracic Society: Measurement properties of field walking tests in chronic respiratory disease. Eur Respir J 44(6):1447-1478

9. Wu G, Sanderson B, Bittner V (2003) The 6-minute walk test: How important is the learning effect? American Heart Journal. 1:129-1331

10. Mak J, Rens N, Savage D, Nielsen-Bowles H, Triggs D, Talgo J et al Reliability and repeatability of a smartphone-based 6-min walk test as a patient-centred outcome measure.European Heart Journal Digital Health 2021May 4; 2(1):77-87

11. Rovedder PME, Fernandes RO, Jacques PS, Ziegler B, de Andrade FP Tarso Roth Dalcin P. Repeatability of the 6-min walk test in non-cystic fibrosis bronchiectasis.Scientific Reports 2020 Nov5;10(1):1-8

12. Ziegler B, Eidt PM, Cpt R, Lacerda C, Ccn O, de Abreu E, Silva F et al (2010) Repeatability of the 6Minute Walk Test in Adolescents and Adults With Cystic Fibrosis. 
13. Jenkins S, Cecins NM (2010) Six-minute walk test in pulmonary rehabilitation: Do all patients need a practice test? Respirology 15(8):1192-6

14. Schmidt K, Vogt L, Thiel C, Jager E, Banzer W, Schmidt K, Vogt L, Thiel C, Jäger E (2013 Jul) Validity of the six-minute walk test in cancer patients. International Journal of Sports Medicine 34(7):631-6

15. Hernandes NA, Wouters EFM, Meijer K, Annegarn J, Pitta F, Spruit MA (2011) Reproducibility of 6minute walking test in patients with COPD. Eur Respir J 38(2):261-7

16. Ferreira V, Lawson C, Ekmekjian T, Carli F, Scheede-Bergdahl C, Chevalier S Effects of preoperative nutrition and multimodal prehabilitation on functional capacity and postoperative complications in surgical lung cancer patients: a systematic review.Supportive Care in Cancer 2021 Mar25;29(10):5597-610

17. Ramos RJ, Ladha KS, Cuthbertson BH, Shulman MA, Myles PS, Wijeysundera DN Association of sixminute walk test distance with postoperative complications in non-cardiac surgery: a secondary analysis of a multicentre prospective cohort study. Canadian Journal of Anesthesia $2021 \mathrm{Apr}$ 1;68(4):514-29

18. Wijeysundera DN Preoperative assessment of functional capacity: Looking beyond the ability to climb stairs.Anesthesiology 2019Vol. 131; p.960-1

19. RJ W (2010) Impaired functional capacity is associated with all-cause mortality after major elective intra-abdominal surgery. Br J Anaesth 105(3):297-303

20. Benzo R, Kelley GA, Recchi L, Hofman A, Sciurba F (2007) Complications of lung resection and exercise capacity: A meta-analysis. Respir Med 101(8):1790-7

21. Nakano J, Fukushima T, Tanaka T, Fu JB, Morishita S Physical function predicts mortality in patients with cancer: a systematic review and meta-analysis of observational studies.Supportive Care in Cancer 2021 Mar26;29(10):5623-34

22. Bartlett JW, Frost C Reliability, repeatability and reproducibility: analysis of measurement errors in continuous variables.Ultrasound in Obstetrics and Gynecology 2008Apr; 31(4):466-75

23. Wijeysundera DN, Beattie WS, Hillis GS, Abbott TEF, Shulman MA, Ackland GL et al Integration of the Duke Activity Status Index into preoperative risk evaluation: a multicentre prospective cohort study. British Journal of Anaesthesia 2020 Mar 1;124(3):261-70

24. Borg GA (1982) Psychophysical bases of perceived exertion. Med Sci Sports Exerc 14(5):377-381

25. Bohannon RW, Crouch R (2016) Minimal clinically important difference for change in 6-minute walk test distance of adults with pathology: a systematic review. J Eval Clin Pract 23:377-381

26. Barberan-garcia A, Ubre M, Roca J, Lacy AM, Burgos F, Risco R et al (2017) Personalised Prehabilitation in High-risk Patients Undergoing Elective Major Abdominal Surgery A Randomized Blinded Controlled Trial.Ann Surg. ; 1-7

27. Chen BP, Awasthi R, Sweet SN, Minnella EM, Bergdahl A, Santa Mina D et al Four-week prehabilitation program is sufficient to modify exercise behaviors and improve preoperative functional walking capacity in patients with colorectal cancer.Supportive Care in Cancer 2016 Aug18;25(1):33-40 
28. American Thoracic Society, Crapo RO, Casaburi R, Coates AL, Enright PL, Maclntyre NR et al (2002 Jul) ATS statement: Guidelines for the six-minute walk test. American Journal of Respiratory and Critical Care Medicine 166(1):111-7

29. Gayda M, Temfemo A, Choquet D, Ahmaïdi S (2004) Cardiorespiratory requirements and reproducibility of the six-minute walk test in elderly patients with coronary artery disease. Arch Phys Med Rehabil 85(9):1538-1543

30. Spencer L, Zafiropoulos B, Denniss W, Fowler D, Alison J, Celermajer D Is there a learning effect when the 6-minute walk test is repeated in people with suspected pulmonary hypertension? Chronic Respiratory Disease 2018;Jan 23;15(4):339-46

31. Kervio G, Carre F, Ville NS (2003) Reliability and intensity of the six-minute walk test in healthy elderly subjects. Med Sci Sports Exerc 35(1):169-174

32. Beriault K, Carpentier AC, Gagnon C, Ménard J, Baillargeon JP, Ardilouze JL et al Reproducibility of the 6-minute walk test in obese adults.International Journal of Sports Medicine 2009 Oct7;30(10):725-7

33. Camarri B, Eastwood PR, Cecins NM, Thompson PJ, Jenkins S (2006) Six minute walk distance in healthy subjects aged 55-75 years. Respir Med 100(4):658-665

34. Spencer LM, Alison JA, Mckeough ZJ (2010) Maintaining benefits following pulmonary rehabilitation: a randomised controlled trial. Eur Respir J 35:571-7

35. José A, Dal Corso S Reproducibility of the six-minute walk test and Glittre ADL-test in patients hospitalized for acute and exacerbated chronic lung disease. Brazilian Journal of Physical Therapy 2015 Jul 14;19(3):235-42

36. Ries JD, Echternach JL, Nof L, Blodgett MG (2009 Jun) Test-retest reliability and minimal detectable change scores for the timed "up \& go" test, the six-minute walk test, and gait speed in people with Alzheimer disease. Phys Ther 89(6):569-579

37. Macchiavelli A, Giffone A, Ferrarello F, Paci M (2020) Reliability of the six-minute walk test in individuals with stroke: systematic review and meta-analysis. Neurol Sci 46:81-87

38. Bland JM, Altman Douglas G Statistical methods for assessing agreement between two methods of clinical measurement.The Lancet 1986 Feb8;327(8476):307-10

39. van Hinte G, Leijendekkers RA, te Molder B, Jansen L, Bol C, Merkx MAW et al Reproducibility of measurements on physical performance in head and neck cancer survivors; measurements on maximum mouth opening, shoulder and neck function, upper and lower body strength, level of physical mobility, and walking ability.PLoS ONE 2020Sep 1;15(9 September 2020).

\section{Figures}




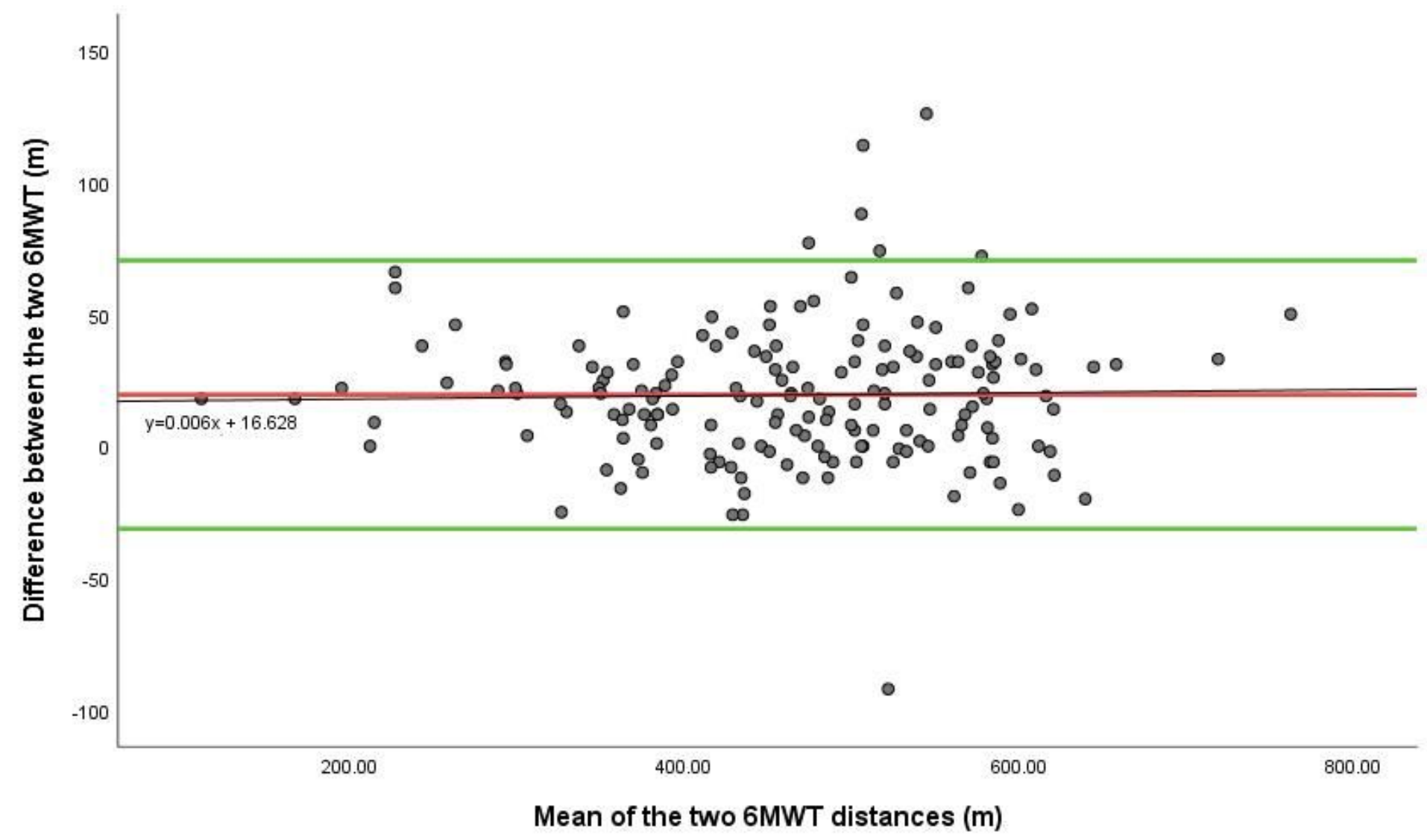

Figure 1

Bland-Altman plot of the difference between two 6-minute walk tests plotted against the mean value of the first attempt. Green lines correspond to the limits of agreement of both tests while red line corresponds to the regression line. 